\title{
Non-fermented Synbiotic Drink Based on Lactic Cheese Whey Which Incorporates Lactobacillus rhamnosus GG and Lactobacillus paracasei
}

\author{
Sima Taheri ${ }^{\mathrm{a}}$, Morteza Khomeiri ${ }^{\mathrm{a}^{*}}$, Mehran Aalami $^{\mathrm{a}}$, And Ali Moayedi ${ }^{\mathrm{a}}$ \\ ${ }^{a}$ Gorgan University of Agricultural Sciences and Natural Resources, Gorgan, Iran \\ ${ }^{*}$ Corresponding author \\ khomeiri@gau.ac.ir \\ TEL: +989111777143
}

Received: 1 November 2018; Published online: 18 October 2019

\begin{abstract}
The use of acid whey in food formulations is one way to reduce the environmental problems associated with its disposal. In the present study, a new formulation of a drinking dessert was prepared using Lactic cheese whey, milk, xanthan gum at 4 levels $(0,0.1,0.2$ and $0.3 \%)$, resistant corn starch at 4 levels $(0,0.5,1$ and 1.5\%), cocoa powder and sugar. Samples containing starch and gum had higher viscosity and were completely stable, with no syneresis and sedimentation after a month of storage at $4{ }^{\circ} \mathrm{C}$. Samples containing $0.3 \%$ xanthan gum and $1 \%$ corn starch were considered as the desired drink based on sensory analysis. Study of the optimal flow behavior indicated that the drinking dessert is a non-Newtonian pseudoplastic fluid, and the Herschel-Bulkily model was the best model to describe the flow behavior. The $\mathrm{pH}$ of the synbiotic dessert containing $L$. GG was almost constant after 7 days of storage at $4{ }^{\circ} \mathrm{C}$, while the $\mathrm{pH}$ of samples containing $L$. paracasei decreased by 0.7 . The population of both probiotic bacteria decreased during storage time at $4{ }^{\circ} \mathrm{C}$. The rate of decrease was higher for L. paracasei than $L$. GG. However, both contained $>10^{6} \mathrm{CFU} \mathrm{mL}^{-1}$, which is necessary for the health benefits of probiotic bacteria.
\end{abstract}

Keywords: Lactic cheese whey (LCW); Drinking dessert; Synbiotic; Lactobacillus rhamnosus GG, Lactobacillus paracasei

\section{Introduction}

Whey is a by-product of cheese making in the dairy industry, which is obtained after the removal of casein from milk (Smithers, 2008). The amount of organic nutrients in whey is remarkable, and is responsible for its high Biological oxygen demand (BOD) and Chemical oxygen demand (COD). Owing to this fact, disposal of whey is expensive (Abdolmaleki, Mazaheri Assadi, \& Jahadi, 2010; Smithers, 2008). Lactic cheese (LC) is widely consumed in Iran, and it is made by coagulation of milk using high acidity yogurt, usually more than $120^{\circ} \mathrm{D}$, and/or or- ganic acids such as citric, lactic or acetic acids. A large amount of lactic cheese whey (LCW) is produced as a by-product of LC production. Drying of LCW to produce a powder is problematic due to its undesirable taste and acidity. Thus, a considerable amount of LCW is directly used in food formulation (Zadow, 1992).

There is an increasing use of probiotic bacteria and prebiotic carbohydrates in fermented and non-fermented dairy foods. Milk and whey are used to make functional foods, which due to their high nutritional value are good choices for human consumption and as carriers for probiotic bac- 
94 | Taheri et al.

teria. For example, sweet and acid whey were studied to make a beverage in a fermented or non-fermented form (Abdolmaleki et al., 2010; Djurić, Carić, Milanović, Tekić, \& Panić, 2004). The sour taste of fermented products is unpleasant for some people, so the production of nonfermented probiotic products would broaden the range of people interested in consuming probiotic products. One of the few studies carried out on non-fermented probiotic beverages is the production of an orange probiotic beverage using Lactobacillus acidophilus (Khamirian, Jooyandeh, Hesari, \& Barzegar, 2016).

A dairy drinking dessert is a new type of beverage that, in addition to near neutral $\mathrm{pH}$, usually has a high viscosity, opaque appearance and complete stability over the shelf-life (Beecher, Drake, Luck, \& Foegeding, 2008). Addition of acid whey, at $\mathrm{pH}$ values below the natural $\mathrm{pH}$ of the milk (6.4-6.6), and starch may cause syneresis or sedimentation in the final product. Because texture, oral sensitivity and stability are three important factors affecting the consumer's opinion about a drinking dessert, selection of an effective hydrocolloid in an appropriate amount can play an important role in consumer's acceptance.

In this study, lactic cheese whey was used, a by-product of the cheese industry, to make a synbiotic drinking dessert which incorporated $L$. rhamnosus GG and L. paracasei, that had a complete stability and desirable sensory properties. Different physicochemical and microbial tests were also performed to determine the properties of this novel product.

\section{Materials and Methods}

\subsection{Probiotic bacterial strain}

Lactobacillus rhamnosus GG (ATCC53103) and Lactobacillus paracasei (L. casei 431) were obtained from Chr. Hansen (Denmark). $10 \mathrm{~g}$ Direct Vat Set (DVS) culture was added to $100 \mathrm{~mL}$ $1.5 \%$ sterilized milk as a stock culture, and was frozen in liquid nitrogen and stored at $-80{ }^{\circ} \mathrm{C}$.

\subsection{Determination of physicochemical properties of LCW}

Physicochemical properties of LCW were analyzed using the following methods: Density using a lactodensimeter (Quevenne, Germany) (AOAC 925.225); $\mathrm{pH}$ by a digital $\mathrm{pH}$ meter (Knick model 766, Germany); acidity by a titration method with $0.1 \mathrm{~N} \mathrm{NaOH}$ in the presence of phenolphthalein as an indicator (AOAC 947.05); soluble solids using a digital refractometer (CETI, Belgium) (AOAC 923.12); dry matter by air drying in an oven (Nuve, Model FN120, Turkey) (AOAC 990.20); ash by incinerating in an electric furnace at $550{ }^{\circ} \mathrm{C}$ (Nabertherm, Germany) (AOAC 945.46); protein by the Kjeldahl method (Behr, Germany) using a factor of 6.38 (AOAC 991.23); and fat by the Gerber method (AOAC 2000.18). The lactose content of whey was determined by an HPLC system (Knauer, Germany), equipped with an analytical column from Eurokat $(300 \times$ $8 \mathrm{~mm}, 10 \mu \mathrm{m})$ and a refractive index detector. Sample preparation was performed as described by Chavez-Servin, Castellote, and Lopez-Sabater (2004). A standard curve was also prepared by HPLC analysis of different concentrations of pure lactose.

\subsection{Preparation of dairy drinking dessert}

In the formulation of this new dairy product, lactic cheese whey, milk, xanthan gum, resistant corn starch, sugar and cacao powder were used. The pre-tests were performed to obtain the proper proportion of milk and whey as the main components of the product. According to the primary tests, the best ratio for milk and whey in the mix was 1:1. Whey with Xanthan gum (Puratox, Belgium) at 4 levels (0, 0.1, 0.2 and $0.3 \%$ ), resistant corn starch (Ingredion, USA) at 4 levels $(0,0.1,0.2$ and $0.3 \%), 5 \%$ sugar and $0.3 \%$ cocoa powder were mixed using a magnetic stirrer (Labtron, Iran). This mixture was sterilized at $110{ }^{\circ} \mathrm{C}$ for $10 \mathrm{~min}$. Then sterilized milk was added and the dessert mix was homogenized by a homogenizer (Heidolph, model D-91126, Germany) (10000 rpm for 2 minutes) which had been

IJFS | October 2019 | Volume 8 | pages 93-104 
Synbiotic drink based on whey $\mid 95$

Table 1: Formulation of 16 different treatments to prepare the drinking desserts

\begin{tabular}{ccc}
\hline Treatments $^{1}$ & Xanthan gum $(\%)$ & Resistant corn starch $(\%)$ \\
\hline 1 & 0 & 0 \\
2 & 0 & 0.5 \\
3 & 0 & 1 \\
4 & 0 & 1.5 \\
5 & 0.1 & 0 \\
6 & 0.1 & 0.5 \\
7 & 0.1 & 1 \\
8 & 0.1 & 1.5 \\
9 & 0.2 & 0 \\
10 & 0.2 & 0.5 \\
11 & 0.2 & 1 \\
12 & 0.2 & 1.5 \\
13 & 0.3 & 0 \\
14 & 0.3 & 0.5 \\
15 & 0.3 & 1 \\
16 & 0.3 & 1.5 \\
\hline
\end{tabular}

${ }^{1}$ In all treatments, whey and milk were used in 1:1 ratio, cacao powder $(0.3 \%)$ and sugar $(5 \%)$

sterilized using 70\% alcohol. In this study, 16 treatments were used for preparation and testing of the desserts (Table 1).

\subsection{Evaluation of storage stability}

Syneresis and sedimentation were analyzed using a volumetric cylinder (Laurent \& Boulenguer, 2003). $12 \mathrm{~mL}$ of each sample was poured into a volumetric cylinder and after one-week storage at $4{ }^{\circ} \mathrm{C}$, the volume of sediment at the bottom of the tube and the volume of water in the upper part of the sample were measured in milliliters. Results were calculated using the following equations:

$$
\begin{gathered}
\text { syneresis }(\%)=\frac{V s \times 100}{V t} \\
\text { sedimentation }(\%)=\frac{V p \times 100}{V t}
\end{gathered}
$$

where $V s$ is the supernatant volume, $V_{P}$ is the sedimentation volume and $V_{t}$ is the total volume of the sample in the tube.

\subsection{Determination of viscosity}

The viscosity of drinking desserts was measured by a viscometer (RV-DV II Brookfield, USA), equipped with a thermal circulator and using spindle NO. S00. All samples were subjected to a different shear rate and finally, depending on the texture of the sample, $15 \mathrm{rpm}$ was selected. Therefore, $16 \mathrm{~mL}$ of the sample was poured into a special cylinder and the viscosity was read at $25{ }^{\circ} \mathrm{C}$.

\subsection{Rheological properties of optimal drinking dessert}

Flow curves were obtained by increasing the speed of shearing from $15 \mathrm{rpm}$ to $120 \mathrm{rpm}$. In order to determine the optimum flow behavior of the optimum sample of drinking dessert, and obtain the rheological parameters, three timeindependent models were used: power-law $(\tau=$ $\left.k \gamma^{n}\right)$, Herschel-Bulkley $\left(k \gamma^{n}+\tau\right)$ and Bingham $\left(\tau=\mu_{p} \gamma+\tau_{0}\right)$ (Bhattacharya \& Bhattacharya, 1994).

In these models, $k$ is the consistency coefficient 
(Pa.sn), $n$ is the flow behaviour index, $\gamma$ is the shear rate, $\tau_{0}$ is the yield stress $(\mathrm{Pa})$ and $\mu_{p}$ is the Bingham plastic viscosity (Pa.s).

\subsection{Sensory analysis}

Samples that were completely stable during refrigerated storage were selected for sensory analysis. Samples were served in cups coded with three random alphabets. 15 trained panelists were asked to rate consistency, taste and mouthfeel on the basis of a 5-point hedonic scale (5really good, 4- good, 3- normal, 2- bad, 1- really bad). The analysis was carried out in two stages. In the first stage, panelists were served samples in three groups of four (during three consecutive days), and for each group, the sample that had the highest score was selected for the second stage. Finally, among the three dessert samples, the sample with the highest score was selected as the desired dessert. It should be noted that due to the importance of mouthfeel for drinking desserts, the score of this parameter was weighted as 2 (Janhøj, Frøst, \& Ipsen, 2008).

\subsection{Preparation of synbiotic drinking dessert}

After selection of the optimal formulation based on stability and sensory analysis, L. rhamnosus GG and L. paracasei culture were inoculated to the beverage individually at $4{ }^{\circ} \mathrm{C}$. Beverage samples were stored in the refrigerator for a week and were analysed for $\mathrm{pH}$, titratable acidity and probiotic viable counts just after production, and 1 , 2, 4 and 7 days after storage.

\subsection{Determination of $\mathrm{pH}$ and titratable acidity}

$\mathrm{pH}$ was measured using a digital $\mathrm{pH}$ meter by direct immersion of the $\mathrm{pH}$ meter electrode in the sample.

Titratable acidity was assessed according to the method of Purwandari, Shah, and Vasiljevic (2007). 10mL of the sample was mixed with $10 \mathrm{~mL} \mathrm{CO}_{2}$ free distilled water and the temperature was adjusted to $22{ }^{\circ} \mathrm{C}$. The $\mathrm{pH}$ meter elec- trode was placed in the sample and the $\mathrm{pH}$ was adjusted to 8.3 with $0.1 \mathrm{~N} \mathrm{NaOH}$. The following equation was used to calculate the results and expressed as ${ }^{o} \mathrm{D}$.

$$
A=V \times 10
$$

$\mathrm{A}=$ acidity percentage, $\mathrm{V}=$ volume of sodium hydroxide consumed in milliliters

\subsection{Enumeration of probiotics viable counts}

The viability of L. rhamnosus GG and L. paracasei was evaluated by selective enumeration according to the method of Tharmaraj and Shah (2003). $10 \mathrm{~mL}$ of sample was diluted in $90 \mathrm{~mL}$ of saline solution $\left(0.85 \mathrm{~g} \mathrm{NaCl} 100 \mathrm{~mL}^{-1}\right.$ distilled water) for the first dilution, and keep diluting with a 1:10 ratio until the appropriate dilution is reached. $1 \mathrm{~mL}$ of appropriate dilutions were pour plated in MRS-Vancomycine agar and incubated under an aerobic condition at $37^{\circ} \mathrm{C}$ for 72 hours and then two consecutive dilutions were counted. The following equation used to calculate the results (Cappuccino \& Welsh, 2018)

$$
N=\frac{\sum C i}{V(n 1+0.1 n 2) d}
$$

where $C$ is the sum of colonies on all plates counted, $v$ is the volume applied to each plate, $n_{1}$ is the number of plates counted at the first dilution, $n_{2}$ is the number of plates counted at the second dilution and $d$ is the dilution factor from which the first count was obtained.

\subsection{Microbial quality control}

Samples were analyzed for enumeration of coliforms, molds and yeasts immediately after production and 1, 2, 4 and 7 days after storage. The test for coliforms was performed according to the Iranian National Standard No. 11166, using Violet Red Bile Agar medium (Merck, Germany), and molds and yeasts according to the Iranian National Standard No. 10154, using Yeast Extract Glucose Chloramphenicol medium (Liofilchem, Italy). 


\subsection{Microbial quality control}

Experiments were replicated three times following a completely randomized design using a factorial arrangement. All data were analyzed using the one-way ANOVA procedure, followed by Duncan multiple comparison tests, using SPSS version 23 (SPSS, USA). Probabilities of $\mathrm{P}<$ 0.05 were considered significant.

\section{$3 \quad$ Results and Discussions}

\subsection{Physicochemical properties of LCW}

The physicochemical properties of LCW used in this study were as follows: $\mathrm{pH}(5.7 \pm 0.8)$, acidity $\left(17.5 \pm 0.44^{\circ} \mathrm{D}\right)$, density $(1.0238 \pm 0)$, dry matter $(6.11 \pm 0.25 \%)$, fat $(0.35 \pm 0.02 \%)$, protein $(0.94 \pm 0.17 \%)$, lactose $(4 \pm 0.01 \%)$ (Fig. 1), salts $(0.46 \pm 0.02 \%)$ and ash $(0.62 \pm 0.01 \%)$. Khamirian et al. (2016) found similar values for whey characteristics except for $\mathrm{pH}$ (6.63) and protein content (0.46) which were higher than those found in the present study. Differences in the process of cheese production can influence the whey characteristics. The difference in protein content could be due to the high efficiency of ultrafiltration in feta cheese production. The $\mathrm{pH}$ reported by Djurić et al. (2004) for acidic whey was 3.63, which could have been related to differences in type (lactic acid, acetic acid or citric acid) and amount of acid used in cheese production. Therefore, the composition of the main constituents of whey varies depending on the type of cheese and the type of milk used (Alsaed et al., 2013).

\subsection{Effect of xanthan gum and resistant starch on syneresis and sedimentation}

Addition of acid whey to a drinking dessert mix makes the milk protein network unstable and a clear layer of serum is formed in the beverage over time. On the other hand, the opinion of consumers is that the drinking dessert should be completely stable. Therefore, in the preparation of drinking desserts, hydrocolloids need to be added. Table 2 shows the values obtained for syneresis and sedimentation of drinking desserts containing different levels of xanthan gum and resistant starch. In the control sample (without starch and xanthan gum), a significant syneresis $(33.33 \%)$ was observed, which can be due to denaturation of casein micelles at a $\mathrm{pH}$ below milk pH (de Kruif, 1998). Other samples containing xanthan gum did not have syneresis after 30 days storage at $4{ }^{\circ} \mathrm{C}$. This is due to the binding of hydrocolloids to the casein micelles, which do not allow casein micelles to aggregate (Syrbe, Bauer, \& Klostermeyer, 1998). However, there was no significant difference between the mean percentage (\%) syneresis and sedimentation in all samples containing different amounts of gum $(\mathrm{P}>0.05)$. This indicates that xanthan gum has a significant effect at the $0.1 \%$ level. In samples containing only starch, sedimentation was observed, which naturally could be due to starch sedimentation. Samples containing both starch and xanthan gum conferred a great stability, with no syneresis and sedimentation after 30 days of storage at $4{ }^{\circ} \mathrm{C}$ (Table 2), which demonstrates that a mix of resistant starch and gum is more effective in the production of a single-phase beverage. Many researchers have investigated the effect of different hydrocolloids on the stability of beverages containing whey (Janhøj et al., 2008; Laurent \& Boulenguer, 2003; Mohammadi, Abbasi, \& Hamidi, 2011). Paraskevopoulou et al. (2003) evaluated the effect of three polysaccharides (pectin, xanthan gum and guar gum) on the stability of whey-milk kefir. They showed that Xanthan gum was the most effective stabilizer at $0.2 \%$ level. Generally, polysaccharides contribute to the formation of a stable colloid system by increasing the viscosity of the aqueous phase and preventing particle movement (Parker, Gunning, Ng, \& Robins, 1995).

\subsection{Effect of xanthan gum and starch on the viscosity of drinking dessert}

The viscosity of dairy desserts is primarily affected by the type and concentration of thickening agents, especially polysaccharide hydrocolloids such as gums and starch. Figure. 2 shows the viscosity analysis of the desserts. There 


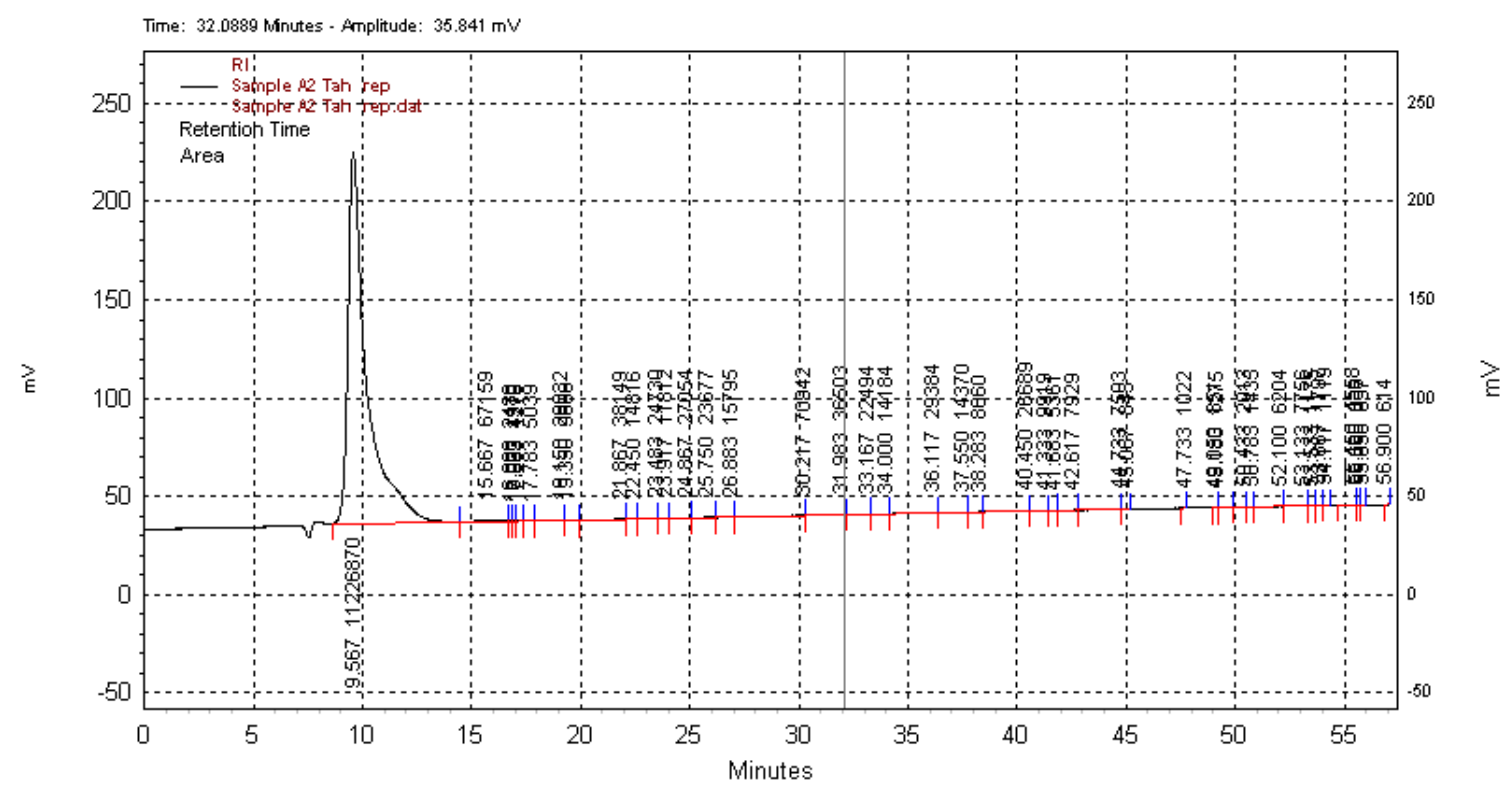

Figure 1: Chromatogram of whey lactose analysis by the HPLC-RI method. Peaks: 1, Lactose

Table 2: Effect of different amounts of gum and starch on sedimentation, syneresis and viscosity

\begin{tabular}{ccc}
\hline Treatment & Sedimentation (\%) & Syneresis (\%) \\
\hline 1 & $0 \pm 0^{c}$ & $33.33 \pm 4.8^{a}$ \\
2 & $61.11 \pm 7.11^{a}$ & $0 \pm 0^{b}$ \\
3 & $58.32 \pm 5.3^{b}$ & $0 \pm 0^{b}$ \\
4 & $50 \pm 0^{b}$ & $0 \pm 0^{b}$ \\
$5-16$ & $0 \pm 0^{c}$ & $0 \pm 0^{b}$ \\
\hline$a-c$ Data with different superscripts are significantly \\
different $(\mathrm{p}<0.05)$ according to Duncan's comparison \\
test. \\
The results are expressed as mean values \pm standard \\
error $(\mathrm{n}=3)$
\end{tabular}

Table 3: Overall scores for different samples in sensory analysis. Stage 1

\begin{tabular}{cccccc}
\hline Sample no. & $\begin{array}{c}\text { Overall score } \\
\text { (out 20) }\end{array}$ & Sample no. & $\begin{array}{c}\text { Overall score } \\
\text { (out 20) }\end{array}$ & Sample no. & $\begin{array}{c}\text { Overall score } \\
\text { (out 20) }\end{array}$ \\
\hline 5 & $8.81 \pm 0.41^{b}$ & 9 & $13.25 \pm 0.84^{a}$ & 13 & $12.87 \pm 1.03^{a}$ \\
6 & $9.68 \pm 0.59^{b}$ & 10 & $13.5 \pm 0.85^{a}$ & 14 & $14.37 \pm 0.74^{a}$ \\
7 & $10.87 \pm 0.9^{a b}$ & 11 & $14.31 \pm 0.89^{a}$ & 15 & $14.43 \pm 0.88^{a}$ \\
8 & $12.43 \pm 0.87^{a}$ & 12 & $11.06 \pm 0.79^{a}$ & 16 & $14.43 \pm 1.08^{a}$ \\
\hline
\end{tabular}

${ }^{a-b}$ Mean values with different superscripts are significantly different $(\mathrm{p}<0.05)$ according to Duncan's comparison test

The results are expressed as mean values \pm standard error $(\mathrm{n}=3)$ 
Synbiotic drink based on whey $\mid 99$

Table 4: Rheological parameters obtained using power law models for the best drinking dessert

\begin{tabular}{cccccccc}
\hline Model & $n$ & RMSE & SSE & $\mathrm{R}^{2}$ & $K$ & $\tau_{0}$ & $\mu$ \\
\hline Power law & 0.298 & 0.395 & 2.34 & 0.998 & 10.11 & - & - \\
Hershel-Bulkley & 0.23 & 0.396 & 2.2 & 0.998 & 10.11 & 3.68 & - \\
Bingham & - & 9.146 & 1255 & 0.953 & - & -119.2 & 4.41 \\
\hline
\end{tabular}

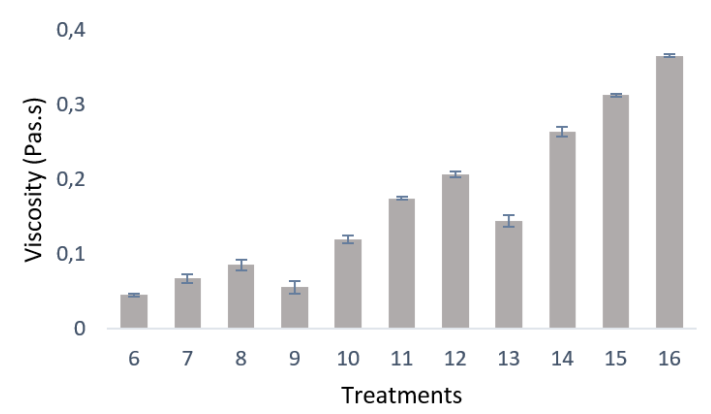

Figure 2: Effect of different percentages of Xanthan gum and resistant corn starch on viscosity of drinking dessert. Results for viscosity of samples 1 to 5 have not been reported, because they had a torque less than 10 .

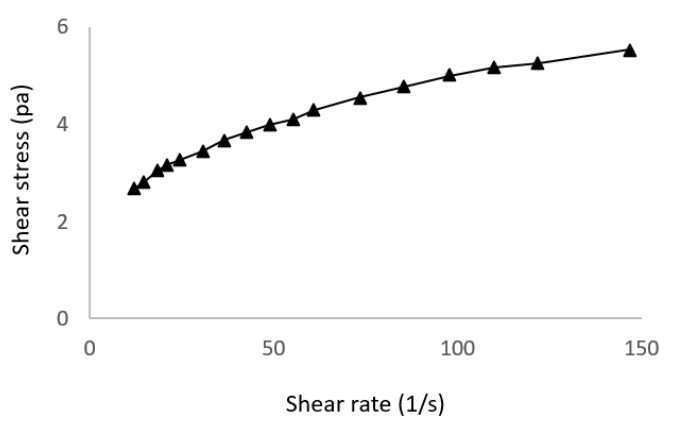

Figure 3: Flow curve of shear stress versus shear rate for the best drinking dessert

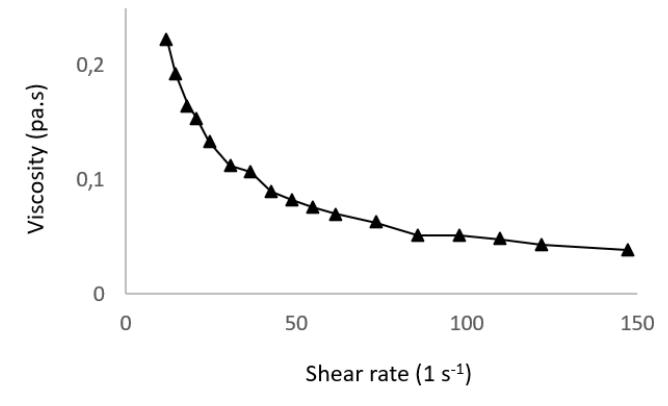

Figure 4: Apparent viscosity versus shear rate for the optimum drinking dessert

was a significant difference between the viscosity of samples for different treatments. With constant gum content and increasing starch content, the viscosity increased and has a maximum at $0.3 \%$ xanthan gum and $1.5 \%$ resistant starch. However, gum and starch in combination had a greater impact on the viscosity than their individual usage (Fig. 2), as a result of hydrocolloids in the continuous phase and starch in the dispersed phase. Sikora, Kowalski, and Tomasik (2008) studied the effect of starch and xanthan gum on viscosity and found that gum and starch individually form two separate phases, but when combined, they form one phase that increases viscosity. Wei, Wang, and Wu (2001) also obtained the same results when using gums and corn starch.

\subsection{Sensory analysis}

There were no significant differences between the samples in each group $(\mathrm{P}>0.05)$, except for group number 3 . The dessert containing $0.1 \%$ gum and $1.5 \%$ starch had the highest overall 
acceptability in the first group. In the second group, due to the increase in gum concentration and the desired consistency, the desirable samples were those containing $0.2 \%$ gum and $1 \%$ starch. In the third group, samples containing $0.3 \%$ gum, $1.5 \%$ starch and $0.3 \%$ gum and $1 \%$ starch had the same score, however, the dessert formulation containing $1 \%$ starch and $0.3 \%$ gum was selected because of lower costs of preparation as a result of less starch. Thus, samples containing $0.1 \%$ gum and $1.5 \%$ starch, $0.2 \%$ gum and $1.5 \%$ starch, $0.3 \%$ gum and $1 \%$ starch were selected for the second stage of sensory analysis (Table 3).

In second stage, samples number 8,11 and 15 gained overall scores of $13.37 \pm 3.9,15.6 \pm 3.2$ and $16.93 \pm 3.3$ respectively. When comparing the three desserts with respect to overall acceptability, there was no significant difference. Nevertheless, the dessert containing $0.3 \%$ gum and $0.1 \%$ starch had the highest score and finally was considered as a best one to prepare the synbiotic dairy dessert.

\subsection{Rheological properties of optimal drinking dessert}

The study of viscosity and flow behavior of fluids is necessary for the design and engineering of equipment and systems, such as pumps, mixers and tubes (Augusto, Cristianini, \& Ibarz, 2012). The rheological properties of dairy desserts mainly depend on the amount of milk fat, the type and concentration of starch and hydrocolloids and their interactions (Torres, Tárrega, \& Costell, 2010). Figures 3 and 4 respectively show shear stress $(\delta)$ versus shear rate $(\gamma)$ and apparent viscosity $(\eta)$ versus shear rate for the optimal drinking dessert containing $0.3 \%$ xanthan gum and $1 \%$ resistant corn starch. With respect to shear stress, the increase in shear rate was not linear. By increasing the shear rate, the apparent viscosity of the sample decreased and shear stress increased, indicating that the dairy dessert had a shear-thinning behaviour. At the lower shear rate, due to the irregular molecular arrangement, the viscosity is high, while with increasing shear rate, the number of molecules that orient to one side is greater and hence the viscos- ity decreases (Mahdian, Mehraban, Karazhian, \& Vaghei, 2014). Such behaviour has already been reported in dairy desserts (Bayarri, Chuliá, \& Costell, 2010; González-Tomás, Bayarri, CollMarqués, \& Costell, 2009). Many research studies have focused on the effect of hydrocolloids to increase the shear-thinning behaviour of foods (Panaras, Moatsou, Yanniotis, \& Mandala, 2011). Because of the increasing viscosity of the serum phase, a condensed polysaccharide network is formed, which is very susceptible to shear rate (Panaras et al., 2011). Xanthan gum is used in dairy products as a semi-solid compound with a gel network which is very similar to a thick three-dimensional gel network. The gel formed by xanthan gum flows freely; therefore, it is extremely shear thinning (Sworn, 2009). The relatively low viscosity, at high shear rate, makes the food containing xanthan gum easy to mix, pour and swallow. Some features, such as inducing high viscosity at low levels and lack of gel formation, make xanthan gum a convenient viscosity control compound as well as a thickening agent, stabilizer and emulsifier in dairy products (Kang \& Pettit, 1993).

According to the flow behaviour index $(n<1)$, the drinking dessert is a non-Newtonian fluid. Although many food fluids have Newtonian behaviour, some liquids and semi-solids have non-Newtonian behaviour. The pseudoplastic behaviour found in this research, has also been reported for frozen soy yogurt containing beta-glucan and modified starch (Rezaei, Khomeiri, Kashaninejad, Aalami, \& MazaheriTehrani, 2017), frozen yogurt containing inulin (Rezaei, Khomeiri, Aalami, \& Kashaninejad, 2014), ice cream containing xanthan gum (Toker, Dogan, Canıyılmaz, Ersöz, \& Kaya, 2013) and dairy dessert based on starch containing inulin (Torres et al., 2010).

Among the models used to determine the flow behaviour of the best drinking dessert, both the power law and Herschel-Bulkley models could be identified as the best because of the high similarity between $\mathrm{R}^{2}$ and RMSE (Table 4 ).

According to the Herschel-Balkley model, the consistency coefficient $(K)$ was 10.11 . This is higher than $K$ value reported for frozen soy yogurt containing 1\% resistant starch (Rezaei et al., 2017) $(K=0.985)$ and lower than dairy dessert

IJFS | October 2019 | Volume 8 | pages 93-104 
starch based (2.5\%) enriched with $7.5 \%$ inulin $(\mathrm{K}=11.81)$ (Torres et al., 2010) and frozen yogurt containing $1 \%$ inulin $(\mathrm{K}=15.45)$ (Rezaei et al., 2014). The consistency of our best drinking dessert was favourable to allow easy drinking with a straw and provide a proper mouthfeel, with acceptable thickness.

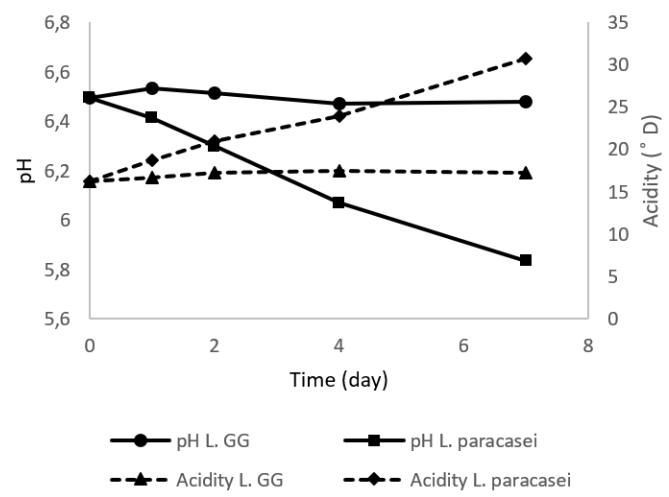

Figure 5: Changes in $\mathrm{pH}$ and acidity for both types of synbiotic drinking dessert at $4{ }^{\circ} \mathrm{C}$

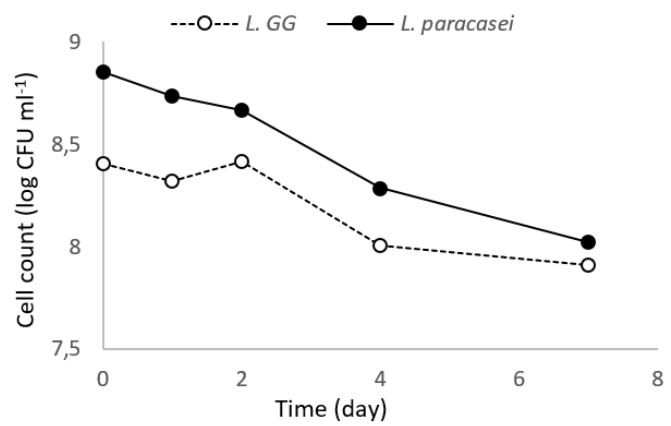

Figure 6: Changes in viable cell counts of probiotic bacteria at $4{ }^{\circ} \mathrm{C}$

\subsection{Changes in $\mathrm{pH}$ and acidity at refrigerator temperature}

As shown in Figure 5, the $\mathrm{pH}$ of the refrigerated dessert containing L. rhamnosus GG was constant $(\mathrm{P}>0.05)$ as L. rhamnosus $\mathrm{GG}$ is not ca- pable of fermenting lactose and casein because of alterations in the nature of anti-terminator (lac $T$ ) and 6-phospho- $\beta$-galactosidase (lac $G$ ) genes (Kankainen et al., 2009). Therefore, the presence of simple sugars, such as glucose and fructose, and proteins, such as whey protein and amino acids as nitrogen sources, are essential for growth and survival of this bacterium. KarltonSenaye and Ibrahim (2013) also reported that $L$. rhamnosus GG slowly reduces the $\mathrm{pH}$ of a dairy dessert during a month under refrigerated storage.

The $\mathrm{pH}$ of the synbiotic drinking dessert containing $L$. paracasei decreased and its differences were significant after a week. As no yeasts and molds and coliforms were detected during oneweek storage, decreasing the $\mathrm{pH}$ could have been due to probiotic bacteria activity. Probiotic bacteria have enzymatic activity of $\beta$-galactosidase, $\beta$-glucosidase and $\alpha$-glucosidase, which are inactive in most probiotic strains at refrigerator temperature but some strains could have $\beta$ galactosidase activity even at refrigerator temperature (Lipovová, Spiwok, Mala, Králová, \& Russell, 2002). Lipovová et al. (2002) studied the activity of the $\beta$-galactosidase enzyme in some lactic acid bacteria, and the results showed that some $L$. paracasei strains at refrigerator temperature are able to ferment lactose, albeit slowly. As shown in Figure 5, the acidity of the samples containing $L$. paracasei increased and decreased the $\mathrm{pH}$. But the acidity of the sample containing L. rhamnosus GG was relatively constant and significant changes were not observed $(\mathrm{P}>$ 0.05). Similar results were obtained by ManiLópez, Palou, and López-Malo (2014). They reported that the acidity of yogurt containing probiotic bacteria $L$. casei, L. reuteri and $L$. acidophilus increased at $4{ }^{\circ} \mathrm{C}$ temperature with respect to decreasing $\mathrm{pH}$.

\subsection{Cell count of probiotic bacteria}

The population of probiotic strains were analyzed for 7 days of storage at $4{ }^{\circ} \mathrm{C}$. In the whole 7 days, because of increasing acidity, the population of L. rhamnosus GG decreased $0.5 \log$ CFU $\mathrm{mL}^{-1}$ compared to the initial time of inoculation

IJFS | October 2019 | Volume 8 | pages 93-104 
$102 \mid$ Taheri et al.

and was significant. The population of $L$. paracasei decreased significantly in all 7 days up to $7.89 \log \mathrm{CFU} \mathrm{mL}{ }^{-1}$. (Fig. 6) The lower counts of $L$. paracasei than $L$. rhamnosus GG. could be due to the intense decrease in $\mathrm{pH}$.

The viable counts of both probiotic bacteria remained above $10^{6} \mathrm{CFU} \mathrm{mL}^{-1}$ during the whole refrigerated storage period which is necessary for the health benefits (Shah, 2007). The results of the present study suggest that it is possible to produce a non-fermented synbiotic drinking dessert, incorporating L. rhamnosus GG, which is not able to reduce the $\mathrm{pH}$ at refrigerated temperature and is not sour.

Sarvari, Mortazavian, and Fazei (2014) studied the population of $L$. animalis and $L$. acidophilus at three different $\mathrm{pH}$ values $(4.5,4.7$ and 4.9$)$ in a mixture of probiotic yogurt. They reported a significant decrease in the population of the probiotic bacteria at lower $\mathrm{pH}$ as observed in this study. Vinderola, Bailo, and Reinheimer (2000) also examined the viability of two probiotic bacteria, B. bifidum BBI and L. acidophilus LAI in Argentinian yogurt during cold storage. Their results showed that the decrease in B. bifidum population was not significant at $\mathrm{pH} 6.5,5.5$, and 4.5 , while the population of $L$. acidophilus significantly decreased at these $\mathrm{pH}$ values.

\section{Conclusion}

In this research, we tried to introduce a new formulation of a dairy drinking dessert as a nonfermented probiotic product using LCW. The results showed that the addition of both xanthan gum and corn starch have a positive effect on the viscosity of the samples and their complete stability during storage at refrigerated temperature. The drinking dessert is a non-Newtonian pseudoplastic fluid, where the Herschel-Bulkley model is the best to describe the behaviour of this food fluid. To produce a non-fermented probiotic product with a sweet taste, it is important to select a probiotic bacteria with the lowest possible activity at refrigerated temperature. L. rhamnosus GG was considered as a suitable species to produce a dairy dessert of non-fermented form due to inactivity at refrigerated temperature.

\section{Acknowledgements}

The authors would like to thank Chr. Hansen for kindly donating the probiotic cultures to our laboratory.

\section{References}

Abdolmaleki, F., Mazaheri Assadi, M., \& Jahadi, M. (2010). Production of a whey-based beverage using several kefir microflora and assessment of its chemical and organoleptic characteristics. Iranian Journal of $\mathrm{Nu}$ trition Sciences \& Food Technology, 4(4). eprint: http: / / nsft.sbmu.ac.ir/article-1250-en.pdf. Retrieved from http://nsft . sbmu.ac.ir/article-1-250-en.html

Alsaed, A. K., Ahmad, R., Aldoomy, H., ElQader, S. A., Saleh, D., Sakejha, H., \& Mustafa, L. (2013). Characterization, concentration and utilization of sweet and acid whey. Pakistan Journal of Nutrition, 12(2), 172-177. Retrieved from https: / / www . researchgate . net / publication / 236347361

Augusto, P. E. D., Cristianini, M., \& Ibarz, A. (2012). Effect of temperature on dynamic and steady-state shear rheological properties of siriguela (spondias purpurea 1.) pulp. Journal of Food Engineering, 108(2), 283289. doi:10.1016/j.jfoodeng.2011.08.015

Bayarri, S., Chuliá, I., \& Costell, E. (2010). Comparing lambda-carrageenan and an inulin blend as fat replacers in carboxymethyl cellulose dairy desserts. rheological and sensory aspects. Food Hydrocolloids, 24(6), 578-587. doi:10.1016/j. foodhyd.2010.02. 004

Beecher, J., Drake, M., Luck, P., \& Foegeding, E. (2008). Factors regulating astringency of whey protein beverages. Journal of Dairy Science, 91 (7), 2553-2560. doi:10.3168/jds. 2008-1083

Bhattacharya, S., \& Bhattacharya, S. (1994). Flow behavior of cooked maize flour suspensions and applicability of mathematical models. Journal of food process engineer- 
ing, 17(3), 263-278. doi:10.1111/j.17454530.1994.tb00339.x

Cappuccino, J. G., \& Welsh, C. (2018). Microbiology, a laboratory manual. 11th edition. Pearson. England.

Chavez-Servin, J. L., Castellote, A. I., \& LopezSabater, M. C. (2004). Analysis of monoand disaccharides in milk-based formulae by high-performance liquid chromatography with refractive index detection. Journal of Chromatography A, 1043(2), 211215. doi:10.1016/j.chroma.2004.06.002

de Kruif, C. (1998). Supra-aggregates of casein micelles as a prelude to coagulation. Journal of Dairy Science, 81(11), 3019-3028. doi:10.3168/jds.S0022-0302(98)75866-7

Djurić, M., Carić, M., Milanović, S., Tekić, M., \& Panić, M. (2004). Development of wheybased beverages. European Food Research and Technology, 219, 321-328. doi:10.1007/ s00217-004-0950-1

González-Tomás, L., Bayarri, S., Coll-Marqués, J., \& Costell, E. (2009). Flow behaviour of inulin-enriched dairy desserts: Influence of inulin average chain length. International Journal of Food Science \& Technology, 44 (6), 1214-1222. doi:10.1111/j.13652621.2009.01949.x

Janhøj, T., Frøst, M. B., \& Ipsen, R. (2008). Sensory and rheological characterization of acidified milk drinks. Food Hydrocolloids, 22(5), 798-806. doi:10 . 1016/j . foodhyd . 2007.03.006

Kang, K. S., \& Pettit, D. J. (1993). Industrial gums. Polysaccharides and Their Derivatives, 341.

Kankainen, M., Paulin, L., Tynkkynen, S., von Ossowski, I., Reunanen, J., Partanen, P., ... de Vos, W. M. (2009). Comparative genomic analysis of lactobacillus rhamnosus gg reveals pili containing a humanmucus binding protein. Proceedings of the National Academy of Sciences of the United States of America, 106(40), 17193-17198. doi:10.1073/pnas.0908876106

Karlton-Senaye, B., \& Ibrahim, S. (2013). Impact of gums on the growth of probiotics. Agro Food Industry Hi-Tech, 24, 10-14.

Khamirian, R. A., Jooyandeh, J., Hesari, J., \& Barzegar, H. (2016). Optimization and investigation on physicochemical, microbial and sensory quality of permeate-based probiotic orange beverage. Food Science and Technology, 14(65). eprint: http:// journals . modares . ac . ir / article - 7 - 112 fa.pdf. Retrieved from http:// journals. modares.ac.ir/article-7-112-fa.html

Laurent, M., \& Boulenguer, P. (2003). Stabilization mechanism of acid dairy drinks (add) induced by pectin. Food Hydrocolloids, 17(4), 445-454. 6th International Hydrocolloids Conference. doi:10.1016/S0268005X (03)00028-6

Lipovová, P., Spiwok, V., Mala, S., Králová, B., \& Russell, N. (2002). Beta-galactosidase activity in psychrotrophic microorganisms and their potential use in food industry. Czech J Food Sci, 20, 43-47. doi:10.17221/ 3508-CJFS

Mahdian, E., Mehraban, S. M., Karazhian, R., \& Vaghei, T. (2014). Study the possibility of symbiotic ice cream production using sugar beet fiber and bifidobacterium bifidum bb12. Journal of Research and Innovation in Food Science and Technology, 3(2), 115128.

Mani-López, E., Palou, E., \& López-Malo, A. (2014). Probiotic viability and storage stability of yogurts and fermented milks prepared with several mixtures of lactic acid bacteria. Journal of Dairy Science, 97(5), 2578-2590. doi:10.3168/jds.2013-7551

Mohammadi, S., Abbasi, S., \& Hamidi, Z. (2011). Effects of hydrocolloids on physical stability, rheological and sensory properties of milk-orange juice mixture. Iranian Journal of Nutrition Sciences \& Food Technology, 5(4). eprint: http://nsft.sbmu.ac.ir/ article-1-409-en.pdf. Retrieved from http: //nsft.sbmu.ac.ir/article-1-409-en.html

Panaras, G., Moatsou, G., Yanniotis, S., \& Mandala, I. (2011). The influence of functional properties of different whey protein concentrates on the rheological and emulsification capacity of blends with xanthan gum. Carbohydrate Polymers, 86(2), 433440. doi:10.1016/j.carbpol.2011.03.044

Paraskevopoulou, A., Athanasiadis, I., Blekas, G., Koutinas, A., Kanellaki, M., \& Kiosseoglou, V. (2003). Influence of 
polysaccharide addition on stability of a cheese whey kefir-milk mixture. Food Hydrocolloids, 17(5), 615-620. doi:10.1016/S0268-005X(02)00122-4

Parker, A., Gunning, P. A., Ng, K., \& Robins, M. M. (1995). How does xanthan stabilise salad dressing? Food Hydrocolloids, 9(4), 333-342. doi:10 . 1016 / S0268 - 005X(09) 80263-4

Purwandari, U., Shah, N., \& Vasiljevic, T. (2007). Effects of exopolysaccharideproducing strains of streptococcus thermophilus on technological and rheological properties of set-type yoghurt. International Dairy Journal, 17(11), 1344-1352. Rheology and Structure of Fermented Milk. doi:10.1016/j.idairyj.2007.01.018

Rezaei, R., Khomeiri, M., Aalami, M., \& Kashaninejad, M. (2014). Effect of inulin on the physicochemical properties, flow behavior and probiotic survival of frozen yogurt. Journal of Food Science and Technology, 51(10), 2809-2814. doi:10 . 1007 / s13197012-0751-7

Rezaei, R., Khomeiri, M., Kashaninejad, M., Aalami, M., \& Mazaheri-Tehrani, M. (2017). Steady and dynamic rheological behaviour of frozen soy yogurt mix affected by resistant starch and beta-glucan. International Journal of Food Properties, 20(sup3), S2688-S2695. doi:10 . $1080 /$ 10942912.2017.1397692

Sarvari, F., Mortazavian, A. M., \& Fazei, M. R. (2014). Biochemical characteristics and viability of probiotic and yogurt bacteria in yogurt during the fermentation and refrigerated storage. Applied Food Biotechnology, $1(1), 55-61$.

Shah, N. P. (2007). Functional cultures and health benefits. International Dairy Journal, 17(11), 1262-1277. Rheology and Structure of Fermented Milk. doi:10.1016/ j.idairyj.2007.01.014

Sikora, M., Kowalski, S., \& Tomasik, P. (2008). Binary hydrocolloids from starches and xanthan gum. Food Hydrocolloids, 22(5), 943-952. doi:10.1016/j. foodhyd.2007.05. 007

Smithers, G. W. (2008). Whey and whey proteins-from 'gutter-to-gold'. Inter- national Dairy Journal, 18(7), 695704. MILESTONE ACHIEVEMENTS IN DAIRY SCIENCE RESEARCH AND THEIR CURRENT AND FUTURE INDUSTRIAL APPLICATIONS. doi:10.1016/j.idairyj.2008.03.008

Sworn, G. (2009). Xanthan gum. In Handbook of hydrocolloids (pp. 186-203). Elsevier.

Syrbe, A., Bauer, W. J., \& Klostermeyer, N. (1998). Polymer science concepts in dairy systems-an overview of milk protein and food hydrocolloid interaction. International Dairy Journal, 8(3), 179-193. doi:10.1016/S0958-6946(98)00041-7

Tharmaraj, N., \& Shah, N. (2003). Selective enumeration of lactobacillus delbrueckii ssp. bulgaricus, streptococcus thermophilus, lactobacillus acidophilus, bifidobacteria, lactobacillus casei, lactobacillus rhamnosus, and propionibacteria. Journal of Dairy Science, 86(7), 2288-2296. doi:10.3168/jds. S0022-0302(03)73821-1

Toker, O. S., Dogan, M., Canıyılmaz, E., Ersöz, N. B., \& Kaya, Y. (2013). The effects of different gums and their interactions on the rheological properties of a dairy dessert: A mixture design approach. Food and Bioprocess Technology, 6(4), 896-908. doi:10. 1007/s11947-012-0787-8

Torres, J., Tárrega, A., \& Costell, E. (2010). Storage stability of starch-based dairy desserts containing long-chain inulin: Rheology and particle size distribution. International Dairy Journal, 20(1), 46-52. doi:10.1016/j.idairyj.2009.08.001

Vinderola, C., Bailo, N., \& Reinheimer, J. (2000). Survival of probiotic microflora in argentinian yoghurts during refrigerated storage. Food Research International, 33(2), 97-102. doi:10.1016/S0963-9969(00)000119

Wei, Y., Wang, C., \& Wu, J. (2001). Flow properties of fruit fillings. Food Research International, 34 (5), 377-381. doi:10.1016/S09639969(00)00178-2

Zadow, J. G. (1992). Whey and lactose processing. doi:10.1007/978-94-011-2894-0 